\title{
Artificial Neural Network Based Determination of the Performance and Emissions of a Diesel Engine Using Ethanol-Diesel Fuel Blends
}

\author{
Özer Can ${ }^{1 *}$, Erkan Öztürk ${ }^{1}$, Erol Arcaklioğlu² \\ 0000-0002-7724-755X, 0000-0002-0002-6142-972X, 0000-0001-8073-5207
}

${ }^{1}$ Automotive Eng. Dept., Faculty of Technology, Pamukkale Univ., Denizli, 20020, Turkey

${ }^{2}$ Mechanical Eng.Dept.,Faculty of Eng. and Natural Sciences, Ankara Yıldırım Beyazıt Univ., Ankara, 06010, Turkey

\begin{abstract}
In this study, the performance and exhaust emission values in a four-stroke, four-cylinder turbocharged Diesel engine fueled with ethanol-diesel fuel blends (10\% and $15 \%$ in volume) were investigated by using Artificial Neural Network (ANN) modeling. The actual data derived from engine test measurements was applied in model training, crossvalidation, and testing. To train the network, fuel injection pressures, throttle positions, engine speed, and ethanol fuel blend ratios were used as input layer in the network. The outputs are the engine performance values (engine torque, power, brake mean effective pressure, and specific fuel consumption) and exhaust emissions $\left(\mathrm{SO}_{2}, \mathrm{CO}_{2}, \mathrm{NO}_{\mathrm{x}}\right.$, and smoke level (N\%)) which were measured in the experiments.

The back-propagation learning algorithm with three different variants, a single layer, and logistic sigmoid transfer function (log-sig) was used in the network. By using the weights of the network, formulations were given for each output. The network for test data yielded the $\mathrm{R}^{2}$ values of 0.999 and the mean \% errors for test data are smaller than $3.5 \%$ for the performance and $8 \%$ for the emissions.
\end{abstract}

Keywords: Artificial neural network; Diesel engine performance; Ethanol-diesel fuel; Exhaust emissions
Research Article

https://doi.org/10.30939/ijastech..805531

Received $\quad 07.10 .2020$

Revised 23.11.2020

Accepted 18.12.2020

* Corresponding author

Özer CAN

ozercan@pau.edu.tr

Adress:Automotive Eng. Dept., Faculty of Technology, Pamukkale Univ., Denizli, Turkey

Tel:+902582964141

\section{Introduction}

Diesel engines are more efficient and durable than spark ignition engines. Thus, they are frequently used in industrial applications, marine transportations and agricultural machines. On the other hand, exhaust emissions of the Diesel engines like $\mathrm{NO}_{\mathrm{x}}$, smoke and $\mathrm{SO}_{\mathrm{x}}$ cause environmental pollution. Stringent governmental regulations on exhaust emissions provide strong encouragement for research into cleaner fuels. Therefore, decreasing the emissions levels of exhaust gases from internal combustion engines has been always regarded as an important problem. Researches on Diesel engine have been focused to approach ideal combustion conditions and many applications were performed to reduce exhaust emissions and improve engine performance. But, exhaust emissions have been existing problems. Required levels from strict legislative regulations are difficult to achieve with only changing of the engine design or exhaust after-treatments. In addition, the high price of diesel fuel is still a disadvantage. As a result, researching suitable and cleaner alternative fuels has been reinforcing its place. Suitable alternative fuels must be found from renewable sources and they should be used without technical modifications in present engine technology.

Diesel engine emissions can be improved by adding organic oxygenated compounds to the No.2 diesel fuel. Ethanol as an oxygenated fuel is biomass based alternative renewable fuel and can be produced from different agricultural products [1-2]. The application of ethanol as a supplementary diesel fuel may reduce environmental pollution, strengthen the agricultural economy, and create job opportunities [3]. The use of ethanol in compression-ignition engines has received considerable attention in recent years [46].

An advantage of ethanol-diesel fuel blends is that a few component changes in the engine are required for their usage. Ethanoldiesel blends homogeneity and phase separation effects depend on hydrocarbon concentrations, wax contents and the ambient temperature of diesel fuels [7-12]. Water concentration of blends also affects solubility of ethanol. For this reason, anhydrous ethanol has a higher miscibility with diesel fuel. Solubilizer addition may be 
required for homogeneity of fuel blends when phase separation occurs [12]. Ethanol addition to diesel fuel results in different physico-chemical changes on diesel fuel properties, particularly reduction in cetane number, viscosity and heating value [1, 7-9]. These alterations influence the spray characteristics, combustion and emissions. It is well known heating value can affect engine torque and power. Ethanol addition results in decreasing in power and torque due to its lower heating value and density [1]. Specific fuel consumption increases with ethanol addition due to these effects. In addition, small adjustments can be required on the injection timing and fuel delivery system or intake air system to obtain restore full power $[13,14]$. The adjustments depend on the ethanol concentration and the resultant effect on it.

Oxygenated diesel fuels can improve exhaust emissions especially soot, particulate matter and $\mathrm{CO}$ emissions $[1,2,5,9,15,16]$. This effect can be explained with several ways: Oxygenated fuels can reduce local fuel/air ratio with additional oxygen for rich regions in premixed combustion phase $[16,17,18]$; separation of some carbon via $\mathrm{C}-\mathrm{O}$ bounds from soot formation process $[17,18,20,21]$; oxidations soot precursors via $\mathrm{OH}$ radicals in the disassociation of oxygenated fuel [17,18, 20-22]. The addition of ethanol to diesel fuel naturally reduces the amount of sulfur in the fuel while causes high $\mathrm{NO}_{\mathrm{x}}$ because of the low cetane number of ethanol [1, 2]. Lowering cetane number raises ignition delays and reduces pressure rates. This effect influences higher peak cylinder pressures, higher peak combustion temperatures and noise. Another approach is that the high latent heat of vaporization of ethanol lowers the flame temperature, resulting in lower $\mathrm{NO}_{\mathrm{x}}$ emissions $[9$, 23].

In internal combustion engines, the combustion process is a complex engineering process. Experimental investigations to measure the performance and emissions from a Diesel engine are complex, time consuming and costly. Mathematical models can be used to predict the emissions from engines. But, their accuracy may not always be satisfactory. One alternative to the mathematical model is the experiment-based approach: for example in Can et al. [1] we presented the results of such a study, which provided the necessary data for the present study. However, although producing good reliable results, this approach itself is expensive and time consuming. The other side, there may be differences between the experimental based studies due to engine fuel metering technology, different measurement devices, test procedures, test conditions, age of vehicles and maintenance history. But they will always give general approach for neural network modeling studies.

Advances have been made in the use of artificial neural-networks (ANNs) and these have been used to predict the exhaust emissions and performance of internal combustion engines [24-29]. In a previous paper, different parameters affecting fuel consumption have been studied by applying neural networks [26]. Another study investigated the effects of different injection pressures and throttle openings on the engine performance and emissions of Diesel engines using ANNs [30]. Neural networks are nonlinear computer algorithms, which can model the behavior of complicated nonlinear processes. They do not need an explicit formulation of physical relationships of concerned problems. In other words, they work on the previous results to make predictions.

In this paper, the performance and exhaust emission values in a Diesel engine running on ethanol fuel as an additive were investigated by using ANN. For this, all the experiments have been performed for both full and partial loads without any modification on a turbocharger Diesel engine with 4-cylinder, 4-stroke, indirect injection by changing injection pressures.

\section{Experimental Apparatus, Test Procedure and Data Col- lecting}

In this study, engine performance and emissions measurements were taken with IDI turbocharged Diesel engine (Ford XLD 418T), test bed (Cussons P8653) and exhaust measurement devices (LoyGaco SN gas analyzer and VLT 2600 smoke meter). The schematic view of the test rig and exhaust analyzers are shown in Figure 1. Some of the specifications of the Diesel engine are summarized in Table 1.

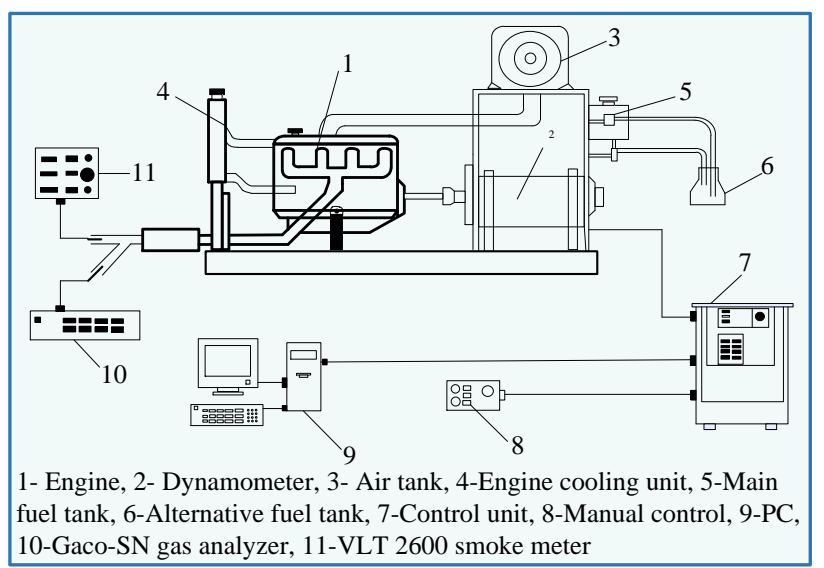

Fig. 1. Schematic of experimental test rig and emissions analyzers.

A Cussons P8653 type engine test bed consists of an air-cooled Eddy-Current electrical dynamometer. The dynamometer operating range area is a maximum of $90 \mathrm{~kW}$ (135 bhp) power absorption, $200 \mathrm{Nm}$ torque and $6000 \mathrm{rpm}$. The test rig has a microprocessorcontrolled thyristor driver for controlling the dynamometer and fully equipped with a full data acquisition system (signal conditioning, display equipments and computerized test accommodating) for measurements of engine operating parameters. The engine speed was measured by an inductive pickup speed sensor, and the sensor was also calibrated by an optical tachometer. Fuel flow measurement was used via a Pelton Wheel type flow meter. Temperatures were measured by $\mathrm{K}$ type thermocouples. A servo actuator was used for controlling the throttle (diesel fuel pump rack) position and incorporates an over-travel device. Its position is adjustable as sensible to facilitate differing engine or testing requirements. A LoyGaco SN gas analyzer using electrochemical sensors was used to measure $\mathrm{CO}(\mathrm{ppm}), \mathrm{SO}_{2}(\mathrm{ppm})$ and $\mathrm{NO}_{\mathrm{x}}(\mathrm{ppm})$. The soot level was measured using a VLT 2600 smoke meter which measurement principle is opacimetric partial flow smoke meter. 
Table 1. Specifications of the test engine

\begin{tabular}{c|c}
\hline Engine Model & Ford-1998 - XLD 418T \\
\hline Engine Type & $\begin{array}{c}\text { 4 Stroke, In-line type, SOCH, } \\
\text { Diesel, IDI, Turbocharged }\end{array}$ \\
\hline $\begin{array}{c}\text { Cylinder number } \\
\text { Displacement }\end{array}$ & 4 cylinder - 1.753 L \\
\hline Stroke and Bore & $82 \mathrm{~mm} \mathrm{-} \mathrm{82.5mm}$ \\
\hline Compression Ratio & $21.5: 1$ \\
\hline Max. Power & 4800 rpm@ $44 \mathrm{~kW}$ \\
Max. Torque & 2500 rpm@ 110 Nm \\
\hline Fuel Injection System & $\begin{array}{c}\text { Lucas DPC rotary distributor } \\
\text { one point fuel injector }\end{array}$ \\
\hline Fuel Injection Advance & 8 CA BTDC \\
\hline $\begin{array}{c}\text { Lubricating System } \\
\text { Cooling System }\end{array}$ & $\begin{array}{c}\text { Full pressured } \\
\text { Pressurized circulation water } \\
\text { cooled }\end{array}$ \\
\hline
\end{tabular}

Experimental engine tests were conducted under steady-state test conditions at different engine loads (Full-100\%, 75\% and 50\%) and different engine speeds (4500-1500 rpm by $500 \mathrm{rpm}$ interval). Before the experiments, fuel engine speed (P) was adjusted to 100 , 200 and 250 bar in addition to the original injection pressure (150 bar). No.2 diesel fuel and ethanol-diesel fuel blends (containing ethanol $10 \%, 15 \%$ in volume) were used in the experiments. The ethanol used in the experiment was 200 proof and $1 \%$ isopropanol added to blends to satisfying homogeneity and prevent phase separation.

The testing procedure is as follows. The experiments were started with No.2 diesel fuel and then ethanol-diesel fuel blends used. After the engine warm-up period, the engine speed was increased to $4500 \mathrm{rpm}$, and then it was decreased by $500 \mathrm{rpm}$ increments to $1500 \mathrm{rpm}$ at constant rack positions. At each point, the engine was kept stable running for a few minutes until exhaust emissions became stabilized and maintained, then measurements were taken. Engine performance results such as torque, power, brake main effective pressure (BMEP), and break specific fuel consumption (SFC) were recorded to the computer from data acquisition system. Exhaust emissions results $\mathrm{CO}(\mathrm{ppm}), \mathrm{SO}_{2}$ (ppm) and $\mathrm{NO}_{\mathrm{x}}(\mathrm{ppm})$ were recorded manually. Each data collecting was repeated three times and the average values of the measurement were given here. Fuel lines and injection pump were cleaned by flush out fuel blends until new fuel blends had taken over for each experiment. Then the engine was left to run for enough time to stabilizing new conditions. Each test was carried out in the same day and under same test environment conditions (air inlet pressure 91 $\mathrm{kPa}$, oil temperature $70^{\circ} \mathrm{C}$, coolant water temperature $110^{\circ} \mathrm{C}$, fuel temperature $40{ }^{\circ} \mathrm{C}$ and $8{ }^{\circ} \mathrm{CA}$ BTDC fuel injection advance). The calibrations of all devices were checked regularly. Accuracies of the measurements and the uncertainties in the calculated results of test equipments are given in Table 2.
Table 2. Accuracies of the measurements and the uncertainties in the calculated results

Calculated uncertainties from engine performance measurements

\begin{tabular}{c|c}
\hline Load $(\mathrm{N})$ & Accuracy $= \pm 0.25 \%$ \\
\hline Speed $(\mathrm{rpm})$ & Accuracy $= \pm 1 \%$ \\
\hline Fuel Flow $\left(\mathrm{Lh}^{-1}\right)$ & Accuracy $= \pm 1 \%$ \\
\hline Temperature $\left({ }^{\circ} \mathrm{C}\right)$ & Accuracy $= \pm 1{ }^{\circ} \mathrm{C}$ \\
\hline Torque $(\mathrm{Nm})$ & Uncertainty $= \pm 0.25 \%$ \\
\hline Power $(\mathrm{kW})$ & Uncertainty $= \pm 1 \%$ \\
\hline BMEP $($ bar $)$ & Uncertainty $= \pm 0.25 \%$ \\
\hline SFC $\left(\mathrm{gkW}^{-1} \mathrm{~h}^{-1}\right)$ & Uncertainty $= \pm 1.7 \%$ \\
\hline VLT $2600-\mathrm{S}$ smoke meter accuracies and measurement ranges \\
\hline Opacity $(\%)$ & Range $=0-100 \%$, Accuracy $= \pm 1 \%$ \\
\hline $\mathrm{LOY} \mathrm{Gaco-SN}$ analyzer accuracies and measurement ranges $^{\mathrm{CO}(\mathrm{ppm})}$ & Range $=0-10000 \mathrm{ppm}$, Accuracy $= \pm 2.5 \mathrm{ppm}$ \\
\hline $\mathrm{SO}_{2}(\mathrm{ppm})$ & Range $=0-2000 \mathrm{ppm}$, Accuracy $= \pm 1 \mathrm{ppm}$ \\
\hline $\mathrm{NO}_{\mathrm{x}}(\mathrm{ppm})$ & Range $=0-1000 \mathrm{ppm}$, Accuracy $= \pm 1 \mathrm{ppm}$ \\
\hline
\end{tabular}

\section{Artificial Neural Networks and The Network Model Em- ployed}

ANNs are computational models that are used to solve complex functions in various applications such as control, data compression etc. A neural network system has three layers, namely, the input layer, the hidden layer and the output layer. The input layer consists of all the input factors, information from the input layer is then processed in the course of one hidden layer, and then the output vector is computed in the output layer. Generally, the hidden and the output layers have an activation function. A sigmoid function as an activation function is a widely used non-linear activation function whose output lies between 0 and 1 .

An important stage when accommodating a neural network is the training step, in which an input is introduced to the network together with the desired outputs, the weights and bias values are initially chosen randomly and the weights are adjusted so that the network attempts to produce the desired output. The weights, after training, contain meaningful information, whereas before training, they are random and have no meaning. When a satisfactory level of performance is reached, the training stops, and the network uses these weights to make decisions.

Many alternative training processes are available, such as backpropagation. The goal of any training algorithm is to minimize the global error level, such as the mean \% error, Root-Mean-Squared (RMS), and the absolute fraction of variance $\left(\mathrm{R}^{2}\right)$ [31]. An important characteristic of this function is differentiable throughout its domain. The errors for hidden layers are determined by propagating back the error determined for the output layer.

In all the models developed, we follow these steps: database collection; analysis and pre-processing of the data; training of the neural network; and the testing of the trained network. In order to train an artificial neural network, the following experimental results were used: Injection pressure $(\mathrm{P})$, engine speed $(\mathrm{N})$, throttle position (TP), and mixture ratio (MR)-ethanol ratio- were used as input layer while performance and exhaust emission characteristics were 
separately used as output layer (Figure 2). For ANNs two data sets are needed: one for training the network and the second for testing it. The usual approach is to prepare a single data set and differentiate it by a random selection. The back-propagation learning algorithm has been used with a single hidden layer. Variants of the algorithm used in the study are Scaled Conjugate Gradient (SCG) and Levenberg-Marquardt (LM). Inputs and outputs are normalized within the range of $(0,1)$. Neurons in the input layer have no transfer function. Logistic sigmoid (logsig) transfer function has been used.

MATLAB software has been used to train and test the ANN on a standard PC.In the training stage to define the output accurately, an increased number of neurons in the hidden layer has been tried. After successful training of the network, the network has been tested with the test data. Using the results produced by the network, statistical methods have been used to make comparisons. Errors occurred at the learning and testing stages are called the RMS and $\mathrm{R}^{2}$, maximum and mean error percentage values, defined as follows respectively:

$$
\begin{aligned}
& R M S=\left([1 / p] \sum_{j}\left|t_{j}-o_{j}\right|^{2}\right)^{1 / 2} \\
& R^{2}=1-\left(\frac{\sum_{j}\left(t_{j}-o_{j}\right)^{2}}{\sum_{j}\left(o_{j}\right)^{2}}\right)
\end{aligned}
$$

$$
\text { Mean\% Error }=\frac{1}{p}-\sum_{j}\left(\frac{t_{j}-o_{j}}{t_{j}}\right) 100
$$

the experiments for each output, 6 or 7 patterns were spared to be used as the test data. The RMS, $\mathrm{R}^{2}$, and the mean error percentage values were used for comparison. The sample patterns are shown in Table 3. Where $t$ is the target value, $o$ is the output value, and $\mathrm{p}$ is the pattern [25]. There are about 115 patterns obtained from

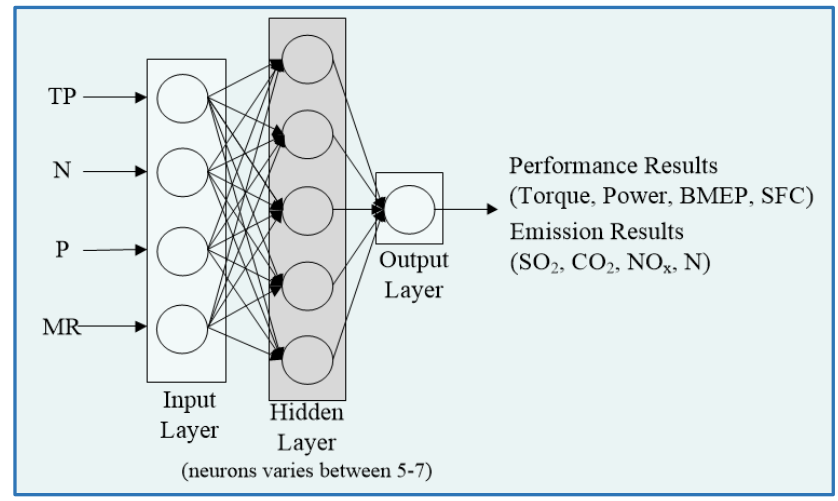

Fig. 2. ANN structure.

Table 3. Samples for input (first three) and outputs.

\begin{tabular}{c|c|c|c|c|c|c|c|c|c|c|c}
\hline $\begin{array}{c}\mathrm{P} \\
(\mathrm{bar})\end{array}$ & $\begin{array}{c}\mathrm{N} \\
(\mathrm{rpm})\end{array}$ & $\begin{array}{c}\mathrm{TP} \\
(\%)\end{array}$ & $\mathrm{MR}$ & $\begin{array}{c}\text { Torque } \\
(\mathrm{Nm})\end{array}$ & $\begin{array}{c}\text { Power } \\
(\mathrm{kW})\end{array}$ & $\begin{array}{c}\mathrm{BMEP} \\
(\mathrm{bar})\end{array}$ & $\begin{array}{c}\mathrm{SFC} \\
\left(\mathrm{gkW}^{-1} \mathrm{~h}^{-1}\right)\end{array}$ & $\begin{array}{c}\mathrm{SO}_{2} \\
(\mathrm{ppm})\end{array}$ & $\begin{array}{c}\mathrm{CO}_{2} \\
(\%)\end{array}$ & $\begin{array}{c}\mathrm{NO}_{\mathrm{x}} \\
(\mathrm{ppm})\end{array}$ & $\begin{array}{c}\mathrm{Smoke} \\
\mathrm{N} \%\end{array}$ \\
\hline 150 & 3000 & 50 & 10 & 86.35 & 27.149 & 6.189 & 318.24 & 39 & 7.3 & 370 & 5.5 \\
\hline 200 & 4000 & 75 & 10 & 88 & 36.88 & 6.31 & 360.36 & 74 & 9.4 & 506 & 6 \\
\hline 250 & 3500 & 100 & 10 & 79 & 28.98 & 5.663 & 341.64 & 67 & 8.3 & 451 & 5.8 \\
\hline 150 & 2000 & 100 & 15 & 106 & 22.22 & 7.6 & 368 & 80 & 11 & 477 & 68.5 \\
\hline 200 & 2500 & 50 & 15 & 76.35 & 20.02 & 5.47 & 333 & 28 & 7.4 & 465 & 6.4 \\
\hline 250 & 4500 & 100 & 15 & 50.48 & 23.8 & 3.618 & 495.75 & 80 & 7.3 & 294 & 6.4 \\
\hline
\end{tabular}

\section{Results and Discussions}

As stated above, inputs of the network are the injection pressure, the engine speed, the throttle position, and the mixture ratio for a Diesel engine running ethanol fuel as an additive to diesel fuel and the outputs are engine performance and emission values.Firstly, 5 hidden neurons in a single hidden layer were used for all algorithms. Generally, we have started the learning stage using the SCG algorithm and continued with using the LM algorithm. Therefore, the resultant hidden layer does not correspond to a single algorithm. Then the number of neurons was increased. The mean $\%$ errors for the training data are very low. In other words, the predicted ANN values are very close to real values.

The formulations of the outputs -the emissions and values of engine performance- obtained from the weights are given with the
Equations (4-11). Using these formulates the emissions and performance of the Diesel engine may be calculated within the error range given in the appendices. The advantage of using these formulations is that they only consist of four mathematical operations, which require lesser computational time.

$$
\begin{aligned}
& \text { Torque }=\frac{1}{1+e^{-(-3.36785 F 1+1.6449 F 2+14.0618 F 3-10.2625 F 4-1.2633 F 5+3.7475)}} \\
& \text { Power }=\frac{1}{1+e^{-(-7.9318 F 1-1.3013 F 2-14.8581 F 3-2.4995 F 4+5.4501 F 5+1.4114)}} \\
& \text { BMEP }=\frac{1}{1+e^{-(-14.7402 F 1-1.2309 F 2+1.7828 F 3+54.2512 F 4+48.2295 F 5+54.1899)}} \\
& \text { SFC }=\frac{1}{1+e^{-(-1.8036 F 1+2.7382 F 2-70.5335 F 3-30.8054 F 4-1.6069 F 5-3.4371 F 6+0.3053)}}
\end{aligned}
$$




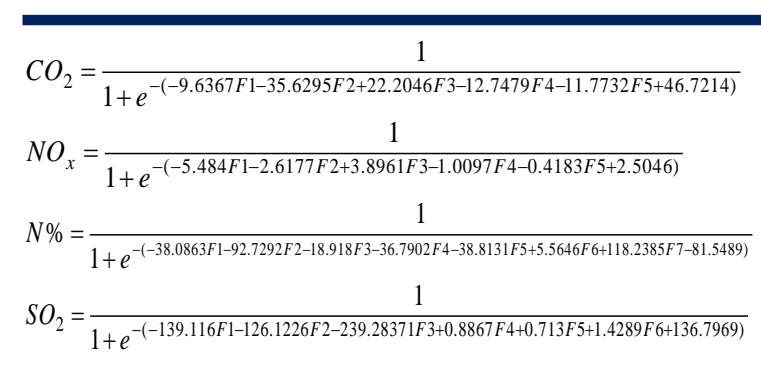

where $\mathrm{Fi}(\mathrm{i}=1,2, . ., 6)$ can be calculated using Equation (12).

$$
F_{i}=\frac{1}{1+e^{-E_{i}}}
$$

Where; $E_{i}$ is given with equations as seen in appendices. The values in the appendix are the weights between the input layer and the hidden layer for the outputs. The values have been given for other users to be used. The equations in the appendix are dependent on the injection pressure, the engine speed, the throttle position, and the mixture ratio, which are the inputs of the network. Coefficients in the Equations (4-11) are the weights, which lie between the hidden and output layers. When using the equations in appendix, $\mathrm{N}, \mathrm{P}, \mathrm{TP}$ and MR values are normalized by dividing them with 5000, 1000, 200, and 20, respectively, to obtain the emissions and performance values in Equations (4-11), Torque, Power, BMEP, SFC, $\mathrm{SO}_{2}, \mathrm{CO}_{2}$, and $\mathrm{NO}_{\mathrm{x}}$ values need to be multiplied by 130,50 , $10,800,110,13$, and 750 , respectively. But, when training the $\mathrm{N} \%$, the Equation (13) was used [25].

$$
N o r_{N \%}=0.8\left[\frac{N \%-N_{\min } \%}{N_{\max } \%-N_{\min } \%}\right]+0.1
$$

where $\mathrm{N}_{\min } \%$, and $\mathrm{N}_{\max } \%$ are minimum and maximum $\mathrm{N} \%$ values (i.e 3.7 and 93 respectively) of all related data, $\mathrm{N} \%$ is the value to be normalized.

In Table 4, the statistical values for engine performance have been shown. As shown in the table, the maximum mean errors for the test data are obtained in the case of Torque and Power. Other mean errors for test data are smaller than $2 \%$. $\mathrm{R}^{2}$ values are very close to 1 , and RMS values are very small for all the performance values.

\begin{tabular}{|c|c|c|c|c|c|c|c|}
\hline & $\begin{array}{l}\text { Hidden } \\
\text { number }\end{array}$ & $\begin{array}{c}\text { RMS } \\
\text { training }\end{array}$ & $\begin{array}{c}\mathrm{R}^{2} \\
\text { training }\end{array}$ & $\begin{array}{c}\text { Mean } \% \\
\text { error training }\end{array}$ & $\begin{array}{c}\text { RMS } \\
\text { test }\end{array}$ & $\begin{array}{l}\mathrm{R}^{2} \\
\text { test }\end{array}$ & $\begin{array}{l}\text { Mean } \% \\
\text { error test }\end{array}$ \\
\hline \multicolumn{8}{|c|}{ Engine Performance Results } \\
\hline Torque $(\mathrm{Nm})$ & 5 & 0.0253 & 0.9984 & 3.83 & 0.0182 & 0.9992 & 3.25 \\
\hline Power $(\mathrm{kW})$ & 5 & 0.0134 & 0.9993 & 2.69 & 0.0131 & 0.999 & 3.22 \\
\hline BMEP (bar) & 5 & 0.0234 & 0.9984 & 3.5 & 0.0103 & 0.9996 & 1.84 \\
\hline $\mathrm{SFC}(\mathrm{g} / \mathrm{kWh})$ & 6 & 0.0116 & 0.9995 & 1.69 & 0.0104 & 0.9996 & 1.94 \\
\hline \multicolumn{8}{|c|}{ Engine Exhaust Results } \\
\hline $\mathrm{SO}_{2}(\mathrm{ppm})$ & 6 & 0.0148 & 0.9994 & 1.99 & 0.0222 & 0.9986 & 3.89 \\
\hline $\mathrm{CO}_{2}(\%)$ & 5 & 0.0171 & 0.9993 & 2.15 & 0.0319 & 0.9978 & 3.81 \\
\hline $\mathrm{NO}_{\mathrm{x}}(\mathrm{ppm})$ & 5 & 0.0282 & 0.9976 & 4.75 & 0.0209 & 0.9986 & 4.99 \\
\hline $\mathrm{N} \%$ & 7 & 0.0104 & 0.9986 & 5.79 & 0.0222 & 0.9786 & 7.77 \\
\hline
\end{tabular}

Table 4. Statistical values of predictions for engine performances and emissions.

In Table 4, the statistical values for exhaust emissions have also been shown. The maximum mean error for test data is also obtained in the case of $\mathrm{N} \%$. Other mean errors for test data are about $4-5 \%$. $\mathrm{R}^{2}$ values are generally very close to 1 for all the performance values.

Figure 3 also compares the results of the engine performance obtained from the experiments and predicted by the ANN in the case of test data while Figure 4 does the same for the exhaust emissions values.

The error levels are generally higher in the case of emission outputs when compared to the performance outputs. We believe that this is mainly due to lack of the in-cylinder conditions related input parameters that govern the complex diesel burning process. How- ever, the accuracy of the model prediction is considered to be improved when input data related to in-cylinder parameters provided.

\section{Conclusions}

The aim of this paper has been to use the neural networks for prediction of engine performance and exhaust emissions in a Diesel engine burning fuel with additives. Results show that the networks can be used as an alternative way in such systems. The RMS error values are smaller than 0.03 and $\mathrm{R}^{2}$ values are about 0.999 . This study demonstrates that the ANNs can be used to determine the engine performance and the emissions instead of complex and time consuming experimental studies using Diesel engines. 

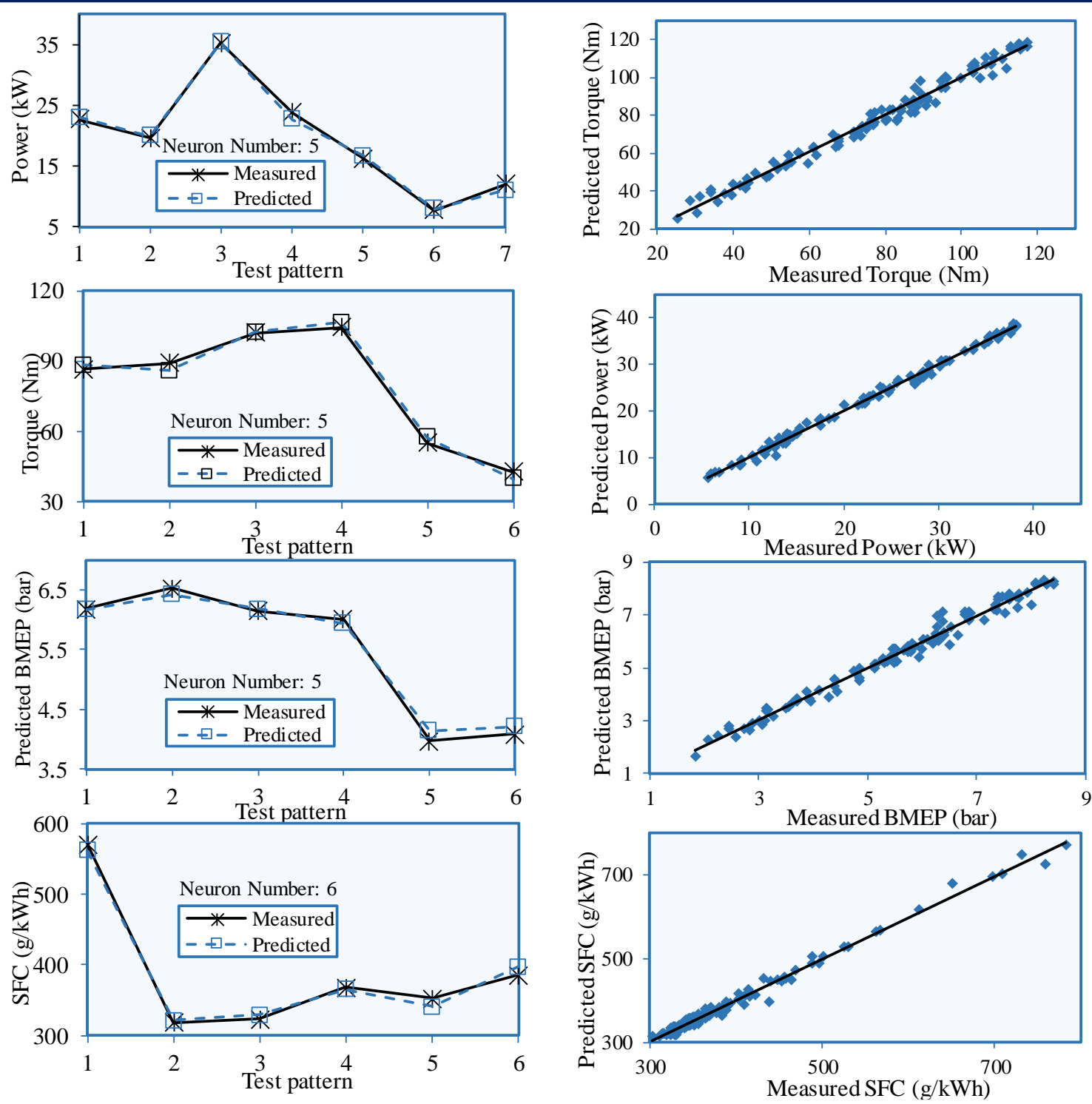

Fig. 3. Measured and predicted results of engine performance of the test data 

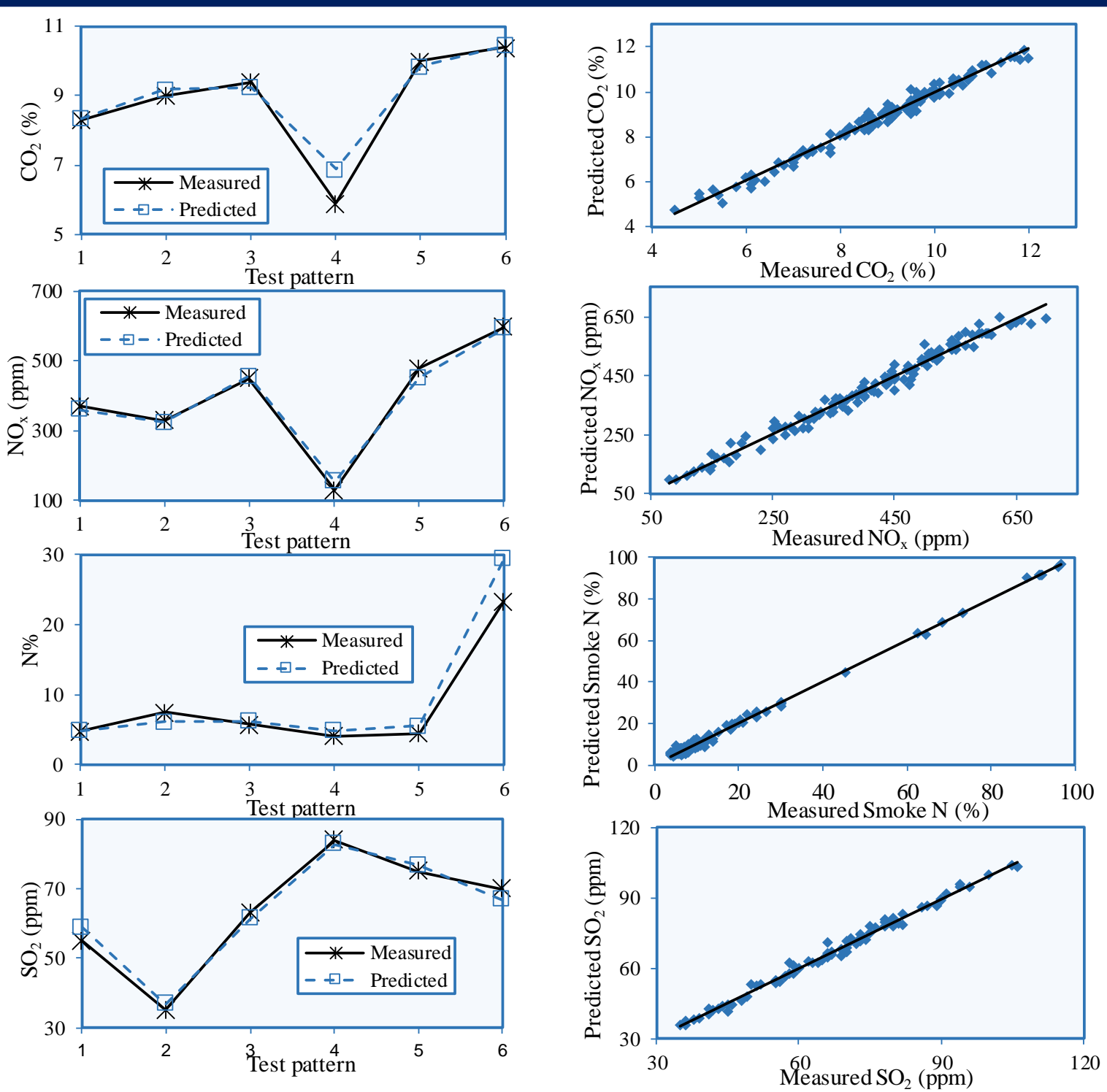

Fig. 4. Measured and predicted results of exhaust emissions of the test data

\section{Acknowledgment}

The authors would like to thank the valuable supports of emeritus Prof. Dr. İsmet ÇELIKTEN.

\section{Conflict of Interest Statement}

The authors declare that there is no conflict of interest.

\section{CRediT Author Statement}

Özer Can: Conceptualization, Supervision, Writing-original draft Erkan Öztürk: Conceptualization, Writing-original draft, Validation Erol Arcaklıoğlu: Methodology, Data curation, Formal analysis.

\section{References}

[1] Can Ö, Çelikten İ, Usta N. Effects of Ethanol Addition on Performance and Emissions of a Turbocharged Indirect Injection Diesel Engine Running at Different Injection Pressures. Energy Conversion and Management. 2004; 45: 2429-2440.

[2] Can O, Celikten İ, Usta N. Effects of Ethanol Blended Diesel Fuel on Exhaust Emissions from a Diesel engine. Journal of Pamukkale University Engineering College. Journal of Engineering Sciences. 2005; 3(11): 325-334.

[3] Balat M, Balat H. Recent Trends in Global Production and Utilization of Bio-Ethanol Fuel. Applied Energy. 2009; 86(11): 2273-2282.

[4] Jinlin Han, Somers LMT, Cracknell R, Joedicke A, Wardle R, Mohan RVR. Experimental Investigation of Ethanol/Diesel Dual-Fuel Combustion in a Heavy-Duty Diesel Engine. Fuel. 2009; 275, 117867. 
[5] Rakopoulos CD, Rakopoulos DC, Kosmadakis GM, Papagiannakis RG. Experimental Comparative Assessment of Butanol or Ethanol Diesel-Fuel Extenders Impact on Combustion Features, Cyclic Irregularity, and Regulated Emissions Balance in Heavy-Duty Diesel Engine. Energy. 2019; 174: 1145-1157.

[6] Liu H, Ma G, Hu B, Zheng Z, Yao M. Effects of Port Injection of Hydrous Ethanol on Combustion and Emission Characteristics in Dual-Fuel Reactivity Controlled Compression Ignition (RCCI) Mode. Energy. 2018; 145: 592-602.

[7] Torres-Jimenez E, Jerma MS, Gregorc A, Lisec I, Dorado MP, Kegl B. Physical and Chemical Properties of Ethanol-Diesel Fuel Blends. Fuel. 2011; 90(2): 795-802.

[8] Singh GN, Bharj RS. Study of Physical-Chemical Properties for 2nd Generation Ethanol-Blended Diesel Fuel in India. Sustainable Chemistry and Pharmacy.2019; 12: 100130.

[9] Kwanchareon P, Luengnaruemitchai A, Jai-In S. Solubility of a Diesel- Biodiesel-Ethanol Blend, Its Fuel Properties, and Its Emission Characteristics from Diesel Engine. Fuel. 2007; 86(7-8): 1053-61.

[10] Jin C, Pang X, Zhang X, Wu S, Ma M, Xiang Y, Ma J, Ji J, Wang G, Liu H. Effects of C3-C5 Alcohols on Solubility of Alcohols/Diesel Blends. Fuel. 2019; 236: 65-74.

[11] Lapuerta M, Armas O, García-Contreras R. Stability of Diesel-Bioethanol Blends for Use in Diesel Engines. Fuel. 2007; 86(10-11): 1351-1357.

[12] Reyes Y, Aranda DAG, Santander LAM, Cavado A, Belchior CRP. Action Principles of Cosolvent Additives in Ethanol Diesel Blends: Stability Studies. Energy Fuels. 2009; 23(5): 2731-2735.

[13] Zhang Bo, Weibiao Fu, Jingsong Gong. Study of Fuel Consumption When Introducing DME or Ethanol into Diesel Engine. Fuel. 2006; 85: 778-782.

[14] Rahimi H, Ghobadian B, Yusaf T, Najafi G, Khatamifar M. Diesterol: An Environment-friendly IC Engine Fuel. Renewable Energy. 2009; 34(1): 335-342.

[15] Bang-Quan H, Shi-Jin S, Jian-Xin W, Hong H. The Effect of Ethanol Blended Diesel Fuels on Emissions from a Diesel Engine. Atmospheric Environment. 2003; 37: 4965-4971.

[16] Kumar V, Singh A P, Agarwal A, Kumar. Gaseous Emissions (regulated and unregulated) and Particulate Characteristics of a Medium-duty CRDI Transportation Diesel Engine Fueled with Dieselalcohol Blends. Fuel. 2020; 278: 118269.

[17] Curran HJ, Fisher EM, Glaude PA, Marinov NM, Pitz WJ, Westbrook CK, Layton DW, Flynn PF, Durrett RP, Loye AO, Akinyemi OC, Dryer FL. Detailed Chemical Kinetic Modelling of Diesel Combustion with Oxygenated Fuels, SAE Technical Paper. 2001; 01-0653.
[18] Kitamura T, Ito T, Senda J, Fujimoto H. Extraction of The Suppression Effects of Oxygenated Fuels on Soot Formation Using a Detailed Chemical Kinetic Model. JSAE Review. 2001; 22(2): 139145.

[19] Choi CY, Reitz RD. An Experimental Study on The Effects of Oxygenated Fuel Blends and Multiple Injection Strategies on DI Diesel Engine Emissions. Fuel. 1999; 78: 1303-1317.

[20] Kocis D, Song K, Lee HS, Litzinger T. Effects of Dimethoxymethane and Dimethylcarbonate on Soot Production in an Optically-accessible DI Diesel Engine. SAE Technical Paper. 2000; 01 2795.

[21] Flynn PF, Durrett RP, Hunter GL, Loye Zu, Akinyemi AO, Dec OC, Westbrook CK. Diesel Combustion: an Integrated View Combining Laser Diagnostics, Chemical Kinetics and Empirical Validation. SAE Technical Paper. 1999; 01-05 09).

[22] Fischer SL, Dryer FL, Curan HJ. The Reaction Kinetics of Dimethyl Ether: High- Temperature Pyrolysis and Oxidation in Flow Reactors. International Journal of Chemical Kinetics. 2000; 32(12): 713740.

[23] Nabi Md. N. Theoretical Investigation of Engine Thermal Efficiency, Adiabatic Flame Temperature, $\mathrm{NO}_{\mathrm{x}}$ Emission and Combustion-related Parameters for Different Oxygenated Fuels. Applied Thermal Engineering. 2010; 30(8-9): 839-844.

[24] Arcaklığlu E, Çavuşoğlu A, Erişen A. Thermodynamic Analyses of Refrigerant Mixtures Using Artificial Neural Networks. Applied Energy. 2004; 78: 219-230.

[25] Sözen A, Arcaklığlu E. Prediction of Solar Potential in Turkey, Applied Energy. 2005; 80: 35-45.

[26] Çelik V, Arcaklioğlu E. Performance Maps of a Diesel Engine. Applied Energy. 2005; 81(3): 247-259.

[27] Polat S, Solmaz H, Calam A, Y1lmaz E. (2020). Estimation of the COV $_{\text {IMEP }}$ Variation in a HCCI Engine. PoliteknikDergisi. 2020; 23(3): 721-727.

[28] Işcan B. ANN Modeling for Justification of Thermodynamic Analysis of Experimental Applications on Combustion Parameters of a Diesel Engine Using Diesel and Safflower Biodiesel Fuels. Fuel. 2020; 279: 118391.

[29] Kurtgoz Y, Karagoz M, Deniz E. Biogas Engine Performance Estimation Using ANN. Engineering Science and Technology an International Journal. 2017; 20(6): 1563-1570.

[30] Arcaklioğlu E, Çelikten İ. Diesel Engine's Performance and Exhaust Emissions. Applied Energy. 2005; 80: 11-22.

[31] D.D. Massie: ECOS'01 on 'Neural Network Fundamentals for Scientists and Engineers'. İstanbul, Turkey, July 2001; 123. 
Appendix - The weights between input layer and hidden layer

\begin{tabular}{|c|c|c|c|c|c|c|}
\hline \multirow{2}{*}{\multicolumn{2}{|c|}{ I }} & \multicolumn{5}{|c|}{$\mathrm{E}_{\mathrm{i}}=\mathrm{C}_{1} * \mathrm{~N}+\mathrm{C}_{2} * \mathrm{P}+\mathrm{C}_{3} * \mathrm{TP}+\mathrm{C}_{4} * \mathrm{MR}+\mathrm{C}_{5}$} \\
\hline & & $\mathrm{C}_{1}$ & $\mathbf{C}_{2}$ & $\mathrm{C}_{3}$ & $\mathrm{C}_{4}$ & $\mathrm{C}_{5}$ \\
\hline \multirow{5}{*}{ 这 } & 1 & -0.1327 & -7.7526 & 1.0346 & -0.3418 & 1.4666 \\
\hline & 2 & -16.0432 & 11.4250 & -5.2921 & 0.0601 & 8.8882 \\
\hline & 3 & 5.3454 & -2.1067 & -29.4798 & -0.1361 & 1.8383 \\
\hline & 4 & -11.7348 & 15.1821 & -0.1816 & 0.4676 & 0.9199 \\
\hline & 5 & -1.6978 & -19.7401 & 0.2808 & -1.0791 & 6.5393 \\
\hline \multirow{5}{*}{ 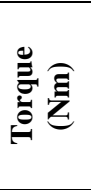 } & 1 & 12.4093 & -5.7701 & 0.4190 & -0.0252 & -7.9696 \\
\hline & 2 & -21.7784 & 20.1334 & 410.9124 & 0.2193 & -96.3410 \\
\hline & 3 & -33.1628 & -8.2200 & -9.8329 & -17.5625 & -26.7508 \\
\hline & 4 & -4.2122 & 12.1803 & 0.6073 & 0.4748 & -1.9267 \\
\hline & 5 & 371.4165 & -714.4903 & -1.0902 & -0.2332 & 31.2976 \\
\hline \multirow{5}{*}{$\sum_{\infty}^{0} \stackrel{0}{\tilde{\Xi}}$} & 1 & 7.9203 & 10.3258 & 0.6616 & 0.7874 & -13.1758 \\
\hline & 2 & 20.9357 & 7.5121 & 5.0042 & 0.5079 & -18.2504 \\
\hline & 3 & -11.8608 & 1.5179 & 108.2371 & 0.0154 & -20.8373 \\
\hline & 4 & 11.0268 & -27.1030 & 0.3529 & -0.7279 & 3.0472 \\
\hline & 5 & -12.3037 & 29.0354 & -0.5668 & 0.7220 & -2.9226 \\
\hline \multirow{6}{*}{ U } & 1 & -31.9840 & 4.8752 & 109.5232 & -0.6643 & -2.2228 \\
\hline & 2 & 1.4636 & 1.1596 & -0.3227 & 12.1267 & -3.7060 \\
\hline & 3 & 8.9652 & 18.9530 & -8.9634 & 1.2486 & -15.1687 \\
\hline & 4 & -18.1432 & -3.4129 & 6.5988 & 0.1106 & 0.3621 \\
\hline & 5 & -7.4386 & 6.4401 & -7.5548 & -0.9879 & 10.0767 \\
\hline & 6 & -29.8743 & -5.0029 & 12.7858 & 0.2740 & 4.0179 \\
\hline \multirow{5}{*}{ Oే } & 1 & 21.1646 & -1.8085 & 2.4734 & -1.7050 & -10.1757 \\
\hline & 2 & -1.4310 & -0.0245 & 2.7552 & 1.7837 & 1.5529 \\
\hline & 3 & 11.7827 & -0.9339 & 1.9726 & -1.0035 & -7.1725 \\
\hline & 4 & -23.5606 & 0.8296 & 12.5756 & -4.0773 & -2.9870 \\
\hline & 5 & 21.7385 & -0.9179 & -15.5781 & 4.9371 & 5.3670 \\
\hline \multirow{6}{*}{ 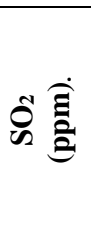 } & 1 & -5.6892 & 1.2179 & 13.3231 & 27.5206 & -15.0405 \\
\hline & 2 & 5.6608 & -1.3680 & -13.4400 & -68.0079 & 35.5101 \\
\hline & 3 & 4.7472 & 0.5980 & 2.9712 & -3.7931 & -7.5929 \\
\hline & 4 & 6.2502 & 8.1678 & -20.9833 & -5.9349 & 5.1584 \\
\hline & 5 & 36.9266 & 23.2051 & 3.2218 & -9.6506 & -16.9786 \\
\hline & 6 & 1.9418 & -41.0557 & -2.0888 & 63.7709 & -10.6366 \\
\hline \multirow{5}{*}{ 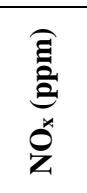 } & 1 & -2.2 & -0.3 & 2.5 & -6.9 & 2.3 \\
\hline & 2 & 6.9 & -2.5 & -21.3 & -0.7 & 7.8 \\
\hline & 3 & -2 & 0.4 & 3.5 & 9.3 & -9.0 \\
\hline & 4 & 2579.9 & -97.4 & -24 & -1 & -586.6 \\
\hline & 5 & 1070 & 3101.4 & 329.9 & 98.4 & -2331.9 \\
\hline \multirow{7}{*}{$\begin{array}{l}\Delta^{\circ} \\
\mathrm{z}\end{array}$} & 1 & -4.5678 & 0.6919 & -43.8188 & -0.5141 & 17.9975 \\
\hline & 2 & 4.1705 & -2.7484 & -7.7771 & 1.6813 & -3.2413 \\
\hline & 3 & 3.3921 & 1.0412 & 10.2207 & -3.1028 & -13.7436 \\
\hline & 4 & -3.9713 & 0.6790 & -70.5632 & -0.2595 & 28.3065 \\
\hline & 5 & 31.4776 & -3.5608 & 88.5933 & 6.9344 & -33.8660 \\
\hline & 6 & 1.5997 & 1.7102 & -10.6150 & -20.3554 & 11.9992 \\
\hline & 7 & 48.1931 & -3.3698 & 11.5554 & 5.1265 & -12.8933 \\
\hline
\end{tabular}

